\title{
Ultrasonographic and Haemato-biochemical Evaluation of Bitches Affected with Cystic Endometrial Hyperplasia-Pyometra Complex
}

\author{
Gopal Samantha ${ }^{1}$, T. Sarath ${ }^{2}$, G. Monica ${ }^{3}$, N. Arunmozhi ${ }^{4}$, \\ P. Sridevi ${ }^{2}$ and Cecilia Joseph ${ }^{2}$ \\ ${ }^{1}$ Veterinary Polyclinic, Barasat, West Bengal, India \\ ${ }^{2}$ Department of Clinics, MVC, Chennai, TANUVAS, Tamil Nadu, India \\ ${ }^{3}$ Department of Veterinary Gynaecology and Obstetrics, C.V.Sc, Tirupati, India \\ ${ }^{4}$ Department of Veterinary Gynaecology and Obstetrics, MVC, Chennai, India \\ *Corresponding author
}

\section{A B S T R A C T}

Keywords

Canine, Pyometra-

CEH complex,

Ultrasonography,

Haematology,

Biochemistry

Article Info

Accepted:

20 May 2018

Available Online:

10 June 2018
The data relating to the present investigation has been generated from ten clinical cases of cystic endometrial hyperplasia-pyometra complex in dogs presented to the Small Animal Veterinary Gynaecology and Obstetrics Unit, Department of Clinics, Madras Veterinary College Teaching Hospital, Chennai during the period from May’ 2017 to July’ 2017. All the dogs were subjected to ultrasonographic examinations and haemato-biochemical studies for confirmatory diagnosis. The uterus was examined to evaluate the integrity of endometrium, presence of exudates, sacculations and cystic hyperplasia of endometrial glands based on the classification with Group A having no cysts, normal endometrial surface and anechoic uterine content, Group B having few and small cysts, normal endometrial surface, anechoic uterine content, Group C havingmany and large cysts, irregular surface and hypertrophic endometrium and Group D having many and large cysts in all the uterus, irregular surface and hypertrophic or atrophic endometrium, hyperechoic uterine content. Haematological parameters viz. haemoglobin, PCV, total leukocyte count, differential leukocyte count, RBC count, platelet count and biochemical parameters like BUN, creatinine, ALT/ SGPT, calcium and phosphorus were analysed statistically and the results are discussed.

\section{Introduction}

Reproductive diseases play an important role in deciding the profitability of the canine breeding ventures. Uterine diseases are the most common cause of failure to conceive in dogs and $25 \%$ of the female dog population developed pyometra by 10 years of age, which is a very high incidence compared to other uterine problems (Hagman, 2004). Pyometra, the bacterial uterine infection is often described as the "major disease of female dogs" since it develops in more than $50 \%$ of all intact female dogs in certain breeds before 10 years of age. The disease is characterized as a hormone induced uterine bacterial 
infection and inflammation, leading to a pusfilled uterus and systemic illness. Several terms such as chronic endometritis, chronic purulent metritis or cystic endometrial hyperplasia complex, have been used in the literature to describe the condition (Fakuda, 2001). Cystic endometrial hyperplasia (CEH)pyometra complex is the most frequently encountered endometrial disorder in bitches (Bigliardi et al., 2004) and its exact pathogenesis is still unknown. $\mathrm{CEH}$ is considered by many authors to be an exaggerated response of the uterus to chronic progestational stimulation during the luteal phase of the estrous cycle, causing an abnormal accumulation of fluid within the endometrial glands and uterine lumen (De Bosschere et al., 2001).

In many cases of CEH secondary bacterial infection occur causing pyometra. The main clinical features of the disease include anorexia, vomiting, polyuria, polydipsia, distension of uterus with or without vaginal discharge and aplastic anaemia. Histologically, the most common lesions observed include cystic endometrial hyperplasia and inflammatory cell infiltration. Historically, pyometra has been most commonly treated by ovariohysterectomy (OHE), once the bitch has been adequately stabilized (Vestegen et al., 2008). Surgical treatment can be recommended in all cases of bitches without significant reproductive value, or when the owner has no strong desire to breed the bitch. Medical treatment of pyometra with compounds promoting expulsion of the uterine pus, in combination with antimicrobials, is an option in some cases depending on the status of uterus and the general condition of the bitch (Gobello et al., 2003). Pyometra is a potentially life threatening condition which requires an early diagnosis to conserve the life of the animal and the evaluation of the clinical status of the bitches may help in predicting the prognosis and treatment.

\section{Materials and Methods}

The data relating to the present investigation has been generated from ten clinical cases of cystic endometrial hyperplasia-pyometra complex in dogs presented to the Small Animal Obstetrics and Gynaecology Unit of Department of Clinics, Madras Veterinary College, Chennai from May' 2017 to July' 2017.A tentative diagnosis of pyometra was made on the basis of medical history and clinical examinations. All the dogs were subjected to ultrasonographic examinations and haemato-biochemical studies for confirmatory diagnosis. Data regarding the general information such as breed, age and weight were collected. The medical history suggestive of pyometra included clinical signs such as anorexia, polyuria, polydipsia, vomition and diarrhoea, presence of vaginal discharges and previous reproductive history if any were also obtained. A detailed clinical examination including rectal temperature, pulse and respiratory rate; presence or absence of vaginal discharges, as evident by visual examination of vulval lips or vaginal aspirate; presence or absence of vulval oedema and gentle abdominal palpation for evidence of uterine distension suggestive of pyometra were carried out.

\section{Ultrasonographic evaluation}

Ultrasonographic examination was carried out using ALOKA Prosound Alpha 6 ultrasonographic machine as per the procedures described by Nyland et al., (2002). The uterus was imaged using a $5 \mathrm{MHz}$ abdominal sector transducer. Animal was restrained on dorsal recumbency and the midventral abdominal region from xyphoid sternum to pubis was prepared by clipping the hair coat. After application of the coupling gel, the curvilinear probe was moved anteriorly and laterally in front of the bladder until the distended horns were visible.If needed, the uterus was scanned with the 
patient in either left or right lateral recumbency. The mid-ventral abdomen was scanned in both sagittal and transverse plane for the examination of uterus. The uterus was examined to evaluate the integrity of endometrium, presence of exudates, sacculations and cystic hyperplasia of endometrial glands. The widest cross-sectional diameter of uterine horns was measured by electronic callipers. The following ultrasound classification was used:

Group I: No cysts, normal endometrial surface and anechoic uterine content.

Group II: Few and small cysts, normal endometrial surface, anechoic uterine content.

Group III: Many and large cysts, irregular surface and hypertrophic endometrium.

Group IV: Many and large cysts in all the uterus, irregular surface and hypertrophic or atrophic endometrium, hyperechoic uterine content.

\section{Haematological and biochemical evaluation}

The haematological and biochemical parameters were investigated using Mindray DC 2500 Vet model haemato-analyzer and BIOSYSTEMS A15 serum auto analyzer equipments respectively in Central Clinical Laboratory Unit of Madras Veterinary College. $5 \mathrm{ml}$ of blood was aseptically collected from all the cases from either radial or cephalic vein into vacutainer tubes with EDTA and non-vacuum blood collection tube without anticoagulant.

The blood samples were processed within 3 to 4 hours of collection for the haematological and biochemical parameters. Haematological parameters viz. haemoglobin, PCV, total leukocyte count, differential leukocyte count, RBC count, platelet count and biochemical parameters like BUN, creatinine, ALT/ SGPT, calcium and phosphorus were analysed.

\section{Statistical analysis}

The data generated from this clinical trial was tabulated and they were subjected to Windows Microsoft Office Excel statistical software package for mean statistical analysis.

\section{Results and Discussion}

The most common complaint reported by owners was the presence of vaginal discharge $(90 \%)$, followed by anorexia $(80 \%)$, vomiting $(70 \%)$, polydipsia $(60 \%)$, and polyuria $(40 \%)$ respectively. Examination of the vulva revealed an oedematous appearance in $60 \%$ of the animals, normal appearance in $30 \%$ of the animals and a shrunken or wrinkled appearance in $10 \%$ of the animals. The vaginal discharge on aspiration was purulent in $44.4 \%$ of the animals, haemorrhagic in $33.3 \%$ of the animals and serosanguinous in $22.2 \%$ of the animals (Table I). Constant licking of the vulva in open cases can act as a cause for oedema but its presence in closed pyometra is difficult to explain (Renukaradhya, 2011).

The most common complaint reported by owners was the presence of vaginal discharge (90\%). Vaginal discharge was absent in one animal (10\%) indicating closed pyometra. This is in accordance with the study of Stone et al., (1988) and Renton et al., (1993) who reported that open pyometra were encountered much frequently than close pyometra.

In a study conducted by Dhaliwal et al., (1998), 88.2\% of the bitches diagnosed with pyometra had a vulval discharge which was indicative of an open cervix and only three had a closed cervix. $33.3 \%$ of the animals exhibited discharge for a period less than one week, $44.4 \%$ of the animals for a period of $1-2$ weeks, $22.2 \%$ for a period of 2-4weeks. 
Igna et al., (2009) reported purulent discharge in all the animals under study whereas Hagman et al., (2006) reported purulent discharge in $58 \%$ of the animals with pyometra. Feldman and Nelson (2004) and Vestegen et al., (2008) found out that the most common clinical finding in bitches with open cervix pyometra is a malodorous, sanguineous to mucopurulent vaginal discharge. The presence of vaginal discharge is dependent on the patency of the cervix and the patency of the cervix in turn influences the general health status of the bitch.

Other clinical signs reported in the present study were vomiting (70\%), polydipsia $(60 \%)$ and polyuria in $40 \%$ of the animals. These results are similar to what has previously been reported in the disease and reflect a local uterine as well as generalised disease. Similar signs in animals affected by pyometra have been reported by Melih et al., (2012). Wheaton et al., (1987) opined that vomiting in affected animals is a poor prognostic sign indicative of a severe form of disease. Fransson (2003) found that $75 \%$ of the animals exhibited vomiting. The presence of vomiting and diarrhoea can be due to adverse effects of higher endotoxic doses as opined by Hardie and Kruse- Elliott (1990).Polydipsia and polyuria has been considered as a classical sign of pyometra and indicates the renal involvement in the disease. Melih et al., (2012) reported polydipsia and polyuria in 18 out of the 20 animals studied, while Fransson (2003) reported that $71 \%$ of the animals under study exhibited polyuria and polydipsia. Hagman et al., (2009) reported a 64\% incidence of polydipsia which is close to the values of the present study.

The endotoxins cause tubular insensitivity to anti diuretic hormone causing development of a secondary nephrogenic diabetes insipidus resulting in reduced urine concentrating ability. This leads to polyuria and compensatory polydipsia (Vestegen et al., 2008). The mean temperature in the affected group was $103.2 \pm 1.6^{0} \mathrm{~F}$ and was found to be higher than the normal physiological range $\left(101-102.5^{\circ} \mathrm{F}\right)$. Sevelius et al., (1990) and Wheaton et al., (1987) also recorded elevated body temperature in $30 \%$ and $40 \%$ of the pyometra cases respectively.

Several authors have reported higher body temperature and correlated that with the presence of Systemic Inflammatory Response Syndrome (SIRS). The presence of fever is supposed to be associated with uterine inflammation and secondary bacterial infection as well as septicaemia or bacteraemia (Fransson, 2003).

Various studies in the past have recorded the importance of temperature as a prognostic tool, as a higher temperature is indicative of the severity of the disease. However, it is evident from the present study that normal, subnormal or elevated temperature can be observed in animals suffering with pyometra.

The mean pulse rate in the affected group was $70.4 \pm 4.8$ per minute and the mean respiratory rate was $22.6 \pm 3.2$ per minute and both were found to be well within the normal physiological ranges of 70-80 per minute and 20-30 per minute respectively. These findings are in agreement with those of Kaymaz et al., (1999) and Kashinath et al., (2009). The systemic manifestations of pyometra can be attributed to the effects of endotoxins released by the circulating bacteria and induces a wide range of biological effects and symptoms such as fever, lethargy and elevation of heart and respiratory rates. According to Hagman (2004) the damage inflicted by the endotoxins on the kidneys causes glomerulonephritis, renal tubular damage, polyuria, polydipsia, electrolyte loss and dehydration. In light of these observations, the findings of the present study are well founded and explained. 


\section{Ultrasonographic evaluation}

Ultrasonographic appearances of open cervix pyometra were seen in Fig-1. The uterine horns contained hyperechoic or anechoic material that showed movement in real time. The uterine wall was thicker than that of closed cervix pyometra (Fig-3). Also, the uterine wall was thickened and irregular and contained multiple tiny anechoic cysts (Fig-6). The luminal cavity included smaller amounts of anechoic fluid than that of closed-cervix pyometra. An ultrasonographic finding of closed-cervix pyometra included variable patterns and was seen in Fig-2. The uterine horns were markedly enlarged and contained hypoechoic material that showed movement in real time. The uterine wall was variable in appearance, from thick and irregular to smooth and thin. Thickened uterine wall had cystic and focal hyperechoic structures. The luminal cavity included anechoic fluid with strong distal enhancement.

In all cases, ultrasound examination revealed the presence of uterine exudates such as blood, mucus, pus and cystic endometrial hyperplasia (Fig-1 to Fig-6). Ultrasound examination was able to clearly evaluate endometrial integrity, variation of uterine wall thickness, uterine distension and cystic endometrial glands. The glands had increased in size and number as endometrial anechoic areas (1-2 mm) within the endometrium. The ultrasound diagnosis of cystic endometrial hyperplasia has shown to be correct for all the cases due to high degree of correlation with Dow's classification of Groups III and IV. Mean values of uterine diameter were $2.4 \mathrm{~cm}$ (Groups I-II), $4.8 \mathrm{~cm}$ (Group III) and $4.2 \mathrm{~cm}$ (Group IV) according with Dow's gross criteria.

In this study all the bitches had clinical signs of pyometra (groups II, III and IV). Ultrasonographic examination is always useful in detecting uterine exudates. It is believed that when clinical signs are severe it is necessary to perform an ultrasonographic examination to diagnose the degree of the lesions (Bigliardi et al, 2004).

Endometrial hyperplasia is the result of cystic deformation of endometrial glands and stromal proliferation of fibroblasts with inflammatory reaction (De Bosschere et al., 2001). Ultrasonographic diff erential diagnosis of CEH in bitches of Groups I and II was not always possible because the lesions were of moderate degree and not identifiable. Cystic endometrial hyperplasia was well identified by ultrasound for bitches in Groups III and IV because of the extent of changes in the tissue.

\section{Haematological studies}

The schematic results of all haematological parameters of ten bitches affected with pyometra were presented in Table-II and mean values were presented in Graph I. The mean $\mathrm{RBC}\left(\times 10^{6} / \mu \mathrm{l}\right)$ was $4.99 \pm 1.01$ and mean $\mathrm{Hb}$ $(\mathrm{mg} / \mathrm{dl})$ was $10.2 \pm 2.24$ in experimental animals. The mean RBC and haemoglobin values were lower than the normal physiological levels suggestive of the existence of anaemia in the pyometra affected bitches. The existence of anaemia in the affected bitches has been described by several authors. Normocytic normochromic anaemia was reported by Greene (2006) and recorded decreased haemoglobin level of $8.3 \mathrm{~g} \%$.

The anaemia in affected dogs can be attributed to toxic depression of bone marrow and or loss of red cells into the uterine lumen. Another possible explanation is that along with the diapedesis of erythrocytes into the uterine lumen, a shortened life span of circulating erythrocytes due to iron deficiency may also be responsible for the anaemia.

The suppression of the reticulo-endothelial system and circulatory systems can result from the deleterious effects of the circulating endotoxins also (Okano et al., 1993). 
The present study has mean PCV (\%) value of $30.19 \pm 6.20$ which considered as an indication of anaemia, several authors has also considered animals with PCV values less than 35\% as anaemic (Wheaton et al., 1987 and Fransson, 2003). It is difficult to determine what the true haematocrit might be in pyometra patients since both dehydration and anaemia may be present concurrently and dehydration can influence the PCV values. However, assessing TEC, Haemoglobin and PCV values along with the hydration status of the animal would help to arrive at a conclusion.

The mean platelet $\left(\times 10^{5} / \mu 1\right)$ count in dogs affected with pyometra was $2.62 \pm 1.07$ and this value was found to be less than the normal physiological value in dogs.

Thrombocytopenia was reported by Fransson (2003). The reason for thrombocytopenia may be attributed to the adverse effect of endotoxins on the bone marrow interfering in the synthesis of platelets.

The mean TLC $\left(\times 10^{3} / \mu \mathrm{l}\right)$ value was $27.82 \pm$ 11.39 and the values were highly above the normal physiological range. Leucocytosis has been considered as a classical sign of pyometra in the bitch. Marked elevation of the total white blood cell count has been recorded by several authors (Hagman et al., 2009). A leucocytosis ranging from 14,000 to $1,80,000$ per micro litre has been reported by Cox and Joshua (1979). Sokolowski (1992) reported white cell counts of $>30000$ cells $/ \mathrm{mm} 3$ in pyometra affected bitches. The marked leucocytosis observed in cases of pyometra is suggested to be due to bone marrow inflammatory response (Sevelius, 1990) and diffused suppurative inflammation of uterus to combat the infection. Mean TLC values similar to the values recorded in the present study were reported by Hagman et al., (2006) and Melih et al., (2012) who reported mean values of $22.8 \pm 11.4 \times 103$ per $\mathrm{cmm}$ and $38.53 \pm 7.28 \times 103$ per $\mathrm{cmm}$ respectively. Therefore, the finding of the present study appears to be well founded.

The mean neutrophil (\%) count recorded in the affected group was $84.6 \pm 5.33$ which was much higher than the normal physiological range. The results were indicative of neutrophilia. This observation drew support from the findings of Schalm et al., (1991). It can also be concluded that the leucocytosis which is a predominant finding in the study is due to neutrophilia exhibited by $>90 \%$ of the animals. Neutrophilia has been recorded by Cox and Joshua (1979) and Hagman et al., (2009). The neutrophilia recorded in the present investigation may be attributed to the defense mechanism of the uterus in response to the invading microorganisms.

Table.1 Nature of vaginal discharge in bitches with pyometra $(n=9)$

\begin{tabular}{|l|l|l|}
\hline Nature of vaginal discharge & Number of animals & Per cent incidence (\%) \\
\hline Serosanguinous & 2 & 22.2 \\
\hline Haemorrhagic & 3 & 33.3 \\
\hline Purulent & 4 & 44.4 \\
\hline
\end{tabular}


Int.J.Curr.Microbiol.App.Sci (2018) 7(6): 2327-2338

Table.2 Schematic results of haematological parameters of ten bitches affected with pyometra

\begin{tabular}{|c|c|c|c|c|c|c|c|c|c|c|}
\hline ID & Breed & Hb & PCV & RBC & WBC & Platele & Neutrop & Lymph & Mono & Eosino \\
No & & g/dl & $\%$ & $\times \mathbf{1 0} / \mu \mathrm{ll}$ & $\times \mathbf{1 0} / \mu \mathrm{ll}$ & $\times \mathbf{1 0} / \mathbf{\mu l}$ & $\%$ & $\%$ & $\%$ & $\%$ \\
\hline $\mathbf{1}$ & Spitz & 12.80 & 36.80 & 5.86 & 32.60 & 1.59 & 89.00 & 7.00 & 4.00 & 0.00 \\
\hline $\mathbf{2}$ & GSD & 9.90 & 30.10 & 4.94 & 14.50 & 1.30 & 74.00 & 21.00 & 4.00 & 1.00 \\
\hline $\mathbf{3}$ & Boxer & 9.30 & 28.00 & 4.37 & 24.00 & 4.22 & 86.00 & 10.00 & 3.00 & 1.00 \\
\hline $\mathbf{4}$ & GSD & 6.00 & 19.20 & 3.02 & 55.00 & 2.88 & 94.00 & 3.00 & 2.00 & 0.00 \\
\hline $\mathbf{5}$ & Spitz & 8.10 & 24.10 & 4.11 & 19.30 & 1.42 & 87.00 & 8.00 & 3.00 & 2.00 \\
\hline $\mathbf{6}$ & Labrador & 10.30 & 30.40 & 5.23 & 24.40 & 2.15 & 83.00 & 12.00 & 4.00 & 1.00 \\
\hline $\mathbf{7}$ & Spitz & 13.00 & 37.20 & 6.12 & 28.20 & 3.50 & 83.00 & 12.00 & 5.00 & 0.00 \\
\hline $\mathbf{8}$ & Dachshund 13.50 & 39.20 & 6.40 & 35.90 & 2.91 & 84.00 & 13.00 & 3.00 & 0.00 \\
\hline $\mathbf{9}$ & Rottweiler & 10.00 & 29.80 & 5.20 & 22.40 & 2.19 & 80.00 & 11.00 & 4.00 & 5.00 \\
\hline $\mathbf{1 0}$ & Labrador & 9.10 & 27.10 & 4.73 & 21.90 & 4.12 & 86.00 & 8.00 & 4.00 & 2.00 \\
\hline
\end{tabular}

Table.3 Schematic results of biochemical parameters of ten bitches affected with pyometra

\begin{tabular}{|l|c|c|c|c|c|c|}
\hline ID & Breed & $\begin{array}{c}\text { BUN } \\
\text { No }\end{array}$ & $\begin{array}{c}\text { Creat } \\
\text { mg/dl }\end{array}$ & $\begin{array}{c}\text { T.Pro } \\
\mathrm{mg} / \mathrm{dl}\end{array}$ & $\begin{array}{c}\text { ALT } \\
\text { IU/L }\end{array}$ & $\begin{array}{c}\text { ALP/L } \\
\text { IU/L }\end{array}$ \\
\hline $\mathbf{1}$ & Spitz & 14.83 & 1.00 & 7.50 & 24 & 146 \\
\hline $\mathbf{2}$ & GSD & 11.00 & 0.63 & 6.50 & 56 & 848 \\
\hline $\mathbf{3}$ & Boxer & 26.52 & 1.07 & 7.10 & 29 & 186 \\
\hline $\mathbf{4}$ & GSD & 12.80 & 0.73 & 6.10 & 39 & 472 \\
\hline $\mathbf{5}$ & Spitz & 40.63 & 1.91 & 7.40 & 42 & 221 \\
\hline $\mathbf{6}$ & Labrador & 72.95 & 1.74 & 7.20 & 48 & 378 \\
\hline $\mathbf{7}$ & Spitz & 24.54 & 1.00 & 7.50 & 34 & 172 \\
\hline $\mathbf{8}$ & Dachshund & 09.74 & 0.90 & 6.10 & 26 & 122 \\
\hline $\mathbf{9}$ & Rottweiler & 23.11 & 1.42 & 7.10 & 32 & 165 \\
\hline $\mathbf{1 0}$ & Labrador & 14.83 & 1.00 & 7.50 & 24 & 146 \\
\hline
\end{tabular}


Graph.I Mean level of haemato-biochemical parameter in bitches affected with pyometra

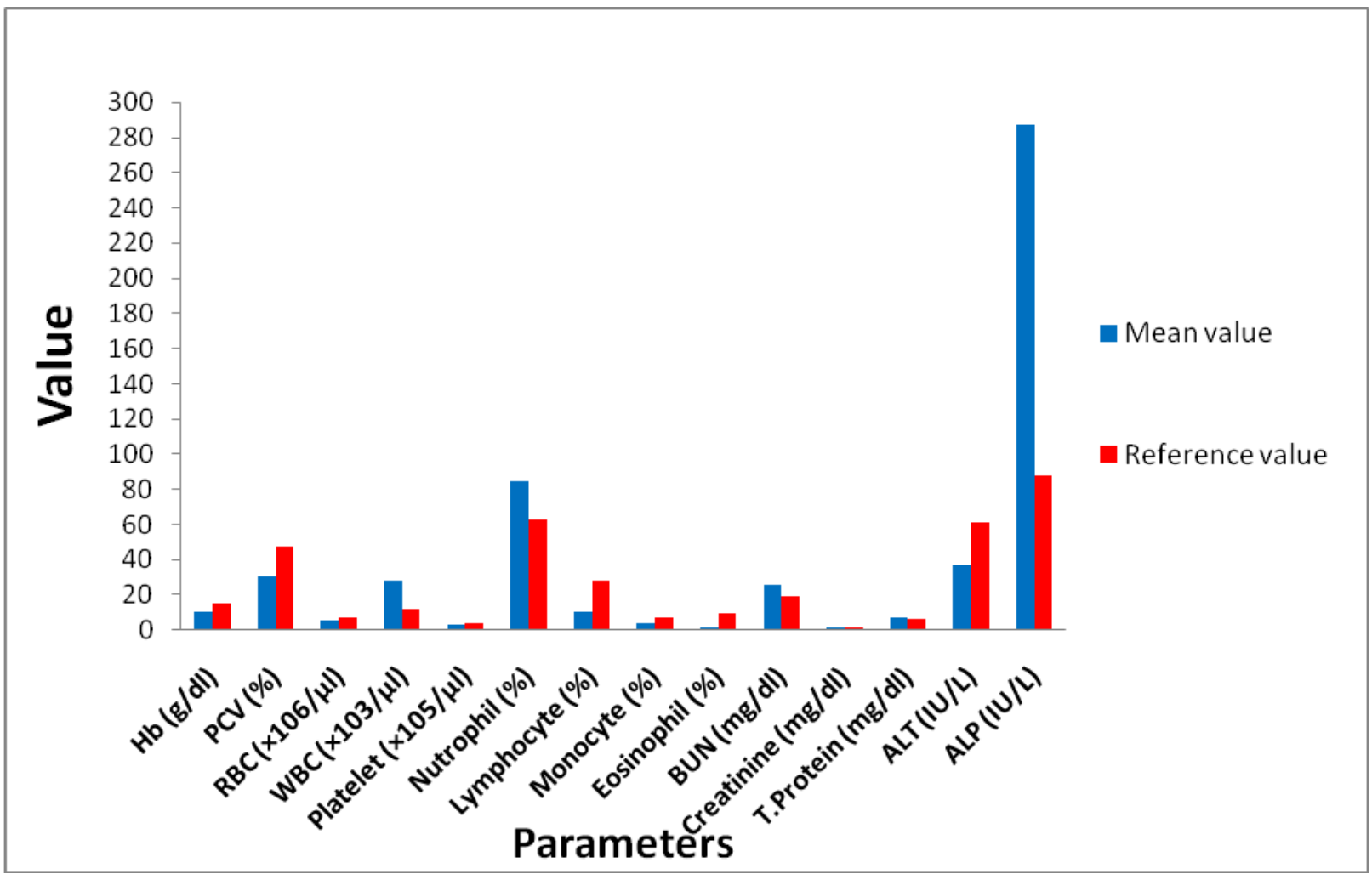

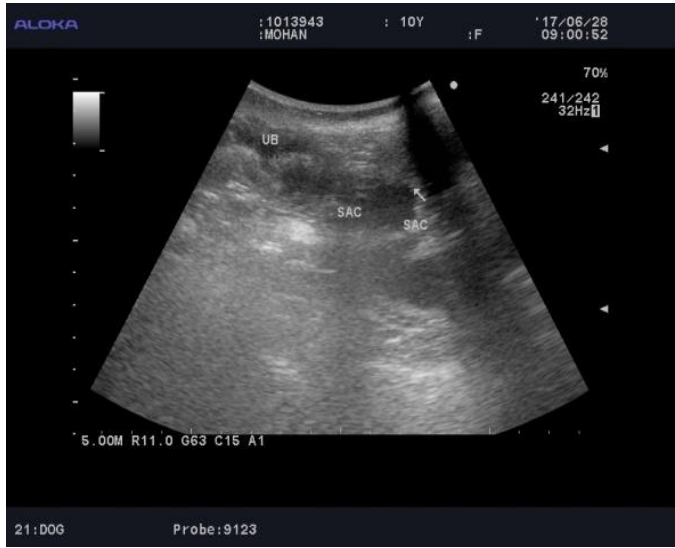

Fig.1 Right uterine horn in a 4 year-old Spitz dog with pyometra (sagittal image). The uterine lumen contains no cysts, normal endometrial surface and anechoic uterine content. [Group II]

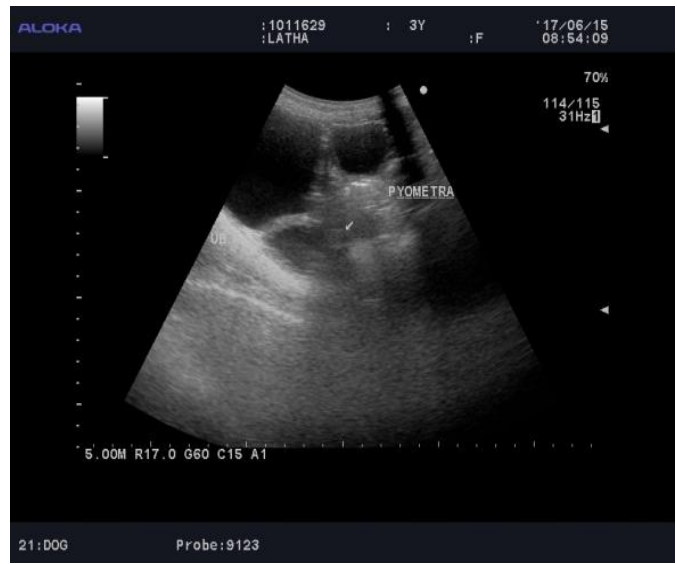

Fig.2 Left and right enlarged uterine horn in a 3 year-old Rottweiler dog with pyometra (transverse image). The uterine horn is markedly enlarged and contains hypoechoic material that showed movement in real time. The uterine wall is thin. The luminal cavity includes anechoic fluid with strong distal enhancement [Group II] 


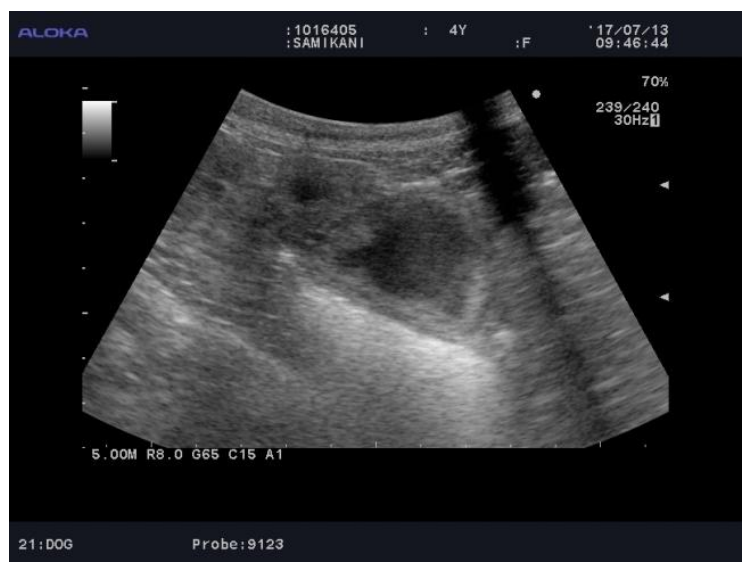

Fig.3 Right and left uterine horns in a 4 year-old Labrador dog with cystic endometrial hyperplasiapyometra complex (transverse image). The uterine horn contains hypoechoic material and the uterine wall is thick. Thickened uterine walls have cystic and focal hyperechoic structures. [Group III]

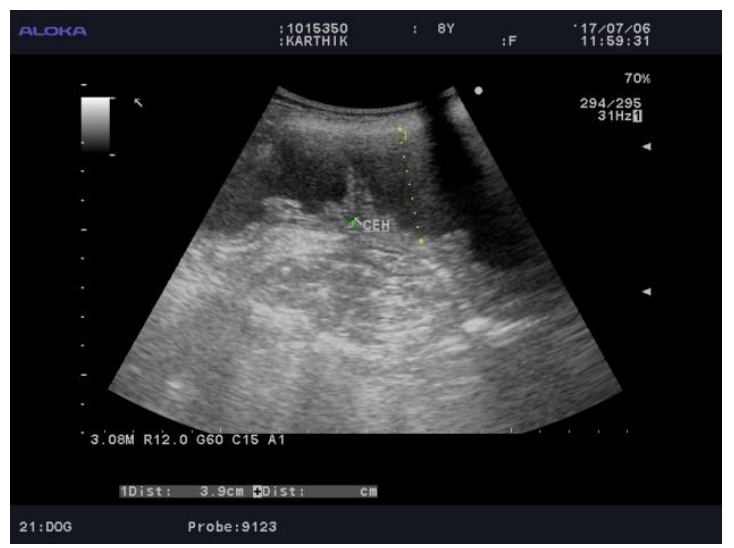

Fig.5 Left uterine horn in a 5-year-old German Shepherd dog with cystic endometrial hyperplasia-pyometra complex (sagittal image). The uterine horns contain hyperechoic material that showed movement in real time. The uterine walls are thick. Thickened uterine wall have cystic and focal hyperechoic structures. [Group IV]

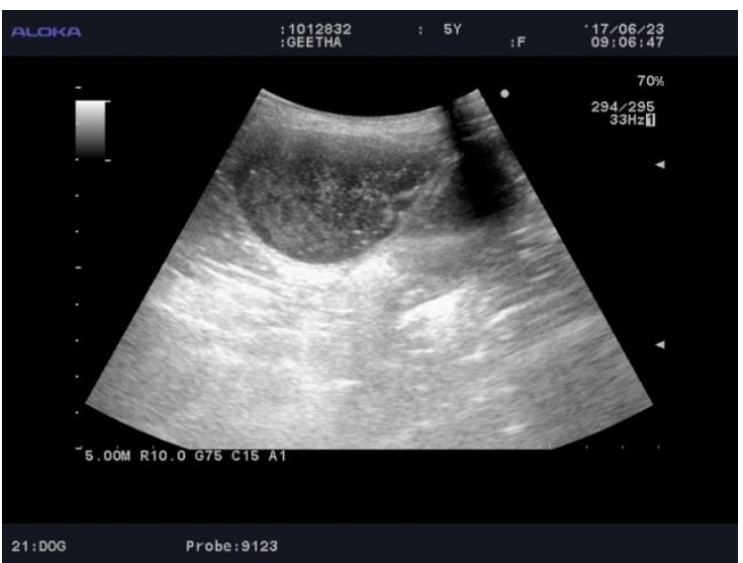

Fig.4 Left uterine horn in a 5 year-old Spitzdog with cystic endometrial hyperplasia- pyometra complex (sagittal image). The uterine wall is thickened and irregular and contains multiple tiny anechoic cysts. The uterine horns contain hyperechoic material that showed movementin real time. [Group III]

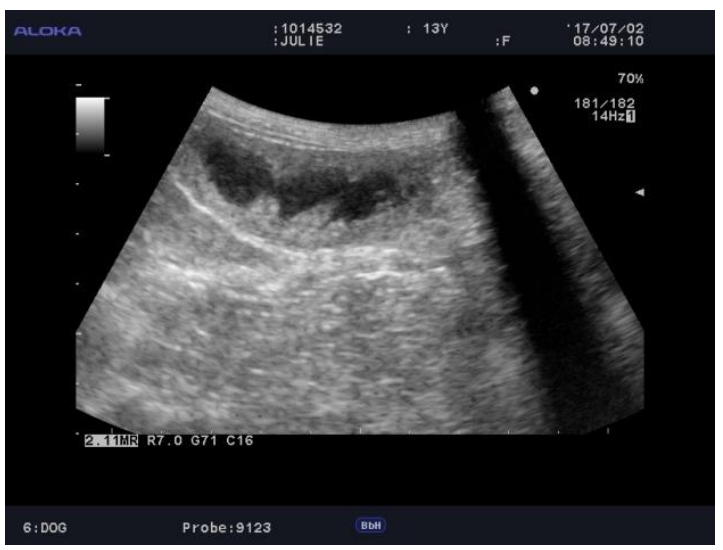

Fig.6 Left uterine horn in a 13-year-old Spitz dog with cystic endometrial hyperplasia- pyometra complex (sagittal image). The uterine wall is thickened and irregular and contains multiple tiny anechoic cysts. Severe endometrial surface lesions and endometrial glands distension are present in the entire uterus [Group IV] 
The mean eosinophilic (\%) count in bitches with pyometra was $1.2 \pm 1.54$ which was nearer to normal physiological range. This is in accordance with the report of Gandotra et al., (1994) who recorded that eosinophils were within the normal limits in the 24 cases he studied.

The mean lymphocyte (\%) values recorded were $10.5 \pm 4.74$. The lymphocyte count was below the normal physiological range in the affected dogs. In agreement with the present study, lymphopenia have been well documented in bitches with pyometra (Kashinath et al., 2009). The low lymphocyte count may be due to absolute increase in neutrophil count as a result of severe suppurative inflammation of the uterus. The suppression of lymphocyte activity and impaired immune response may also be induced by endotoxaemia and bacterial products.

The mean monocyte (\%) count recorded in bitches with pyometra was $3.6 \pm 0.84$. The count was elevated than the normal animals. This is in accordance with the studies of Kasinath et al., (2009). The significant increase in monocyte count may be attributed to the chronicity of the condition in some animals resulting in a chronic inflammatory response.

\section{Biochemical studies}

The schematic results of all biochemical parameters of ten bitches affected with pyometra were presented in Table-III and mean values were presented in Graph I.

The mean BUN (mg/dl) value in affected animals was $25.27 \pm 19.14$ which was above the normal physiological range. This is similar to the findings of Stone et al., (1988)and Wheaton et al., (1987) who reported mean BUN values of $45.1 \pm 26.7$ $\mathrm{mg} / \mathrm{dl}$ and $20 \mathrm{mg} / \mathrm{dl}$ respectively. Wheaton et al., (1987) concluded that elevated blood urea nitrogen level seen in some cases in their study were most often a result of pre- renal uraemia as there was a lowered incidence of elevated creatinine levels as similar to the present study. It is possible that elevated blood urea nitrogen levels observed in nearly $50 \%$ of the bitches in the present study was a result of pre renal uremia due to dehydration.

The mean Creatinine $(\mathrm{mg} / \mathrm{dl})$ values in the affected animals was $1.10 \pm 0.44$. The mean value recorded in the affected group was above the normal physiological value. This is similar to the findings of Wheaton et al., (1987) who reported mean creatinine values of $>1.5 \mathrm{mg} / \mathrm{dl}$. Azotemia in canine pyometra is seen in $15-31 \%$ of the cases (increased serum creatinine and/or elevated BUN). In the present study although there is an elevation in the BUN and creatinine values, the increase appears to be mild. This finding is similar to the report of Fransson (2003) who recorded an incidence of increased BUN in only $4 \%$ of the animals, whereas a decreased BUN was reported in $10 \%$ of the animals. He attributed this lower level to the polyuria, hepatic insufficiency and decreased protein intake present in the affected dogs.

The mean Total Protein $(\mathrm{mg} / \mathrm{dl})$ values in the affected animals was $6.96 \pm 0.53$. The mean value recorded in the affected animals was within the normal physiological value. This is similar to the findings of Stone et al., (1988) and Wheaton et al., (1987).

This means that albumin was lost through the kidney and/or was under-produced by hepatic disease, but levels of acute phase proteins such as C-reactive protein and gammaglobulin, which are produced in response to chronic antigen stimulation, were increased as an acute and chronic inflammatory reaction (Lee et al., 2016). 
In the present study, the mean ALT (IU/L) concentration in the affected animals was 37.3 \pm 10.18 and appeared to be well within the normal ranges. In pyometra cases alanine amino transferase is usually within the normal limits (Hagman et al., 2009) and mild to moderate increase in the ALT concentrations in some animals encountered in the present study may be due to the hepato-cellular damage caused by septicaemia and /or due to diminished hepatic circulation and cellular hypoxia in the dehydrated bitch as stated by Nelson and Feldman (1986).

In the present study, the mean ALP (IU/L) concentration in the affected animals was $287.6 \pm 226.4$ and appeared to be higher than the normal ranges. This indicated that toxemia originating from pyometra may inhibit synthesis of liver enzymes and damage the hepatic membrane (Bigliardiet al.2004).

In the present study is concluded that the analysis of various parameters helps in the assessment of the clinical status of the bitches and in prediction of the prognosis. The ultrasonographical examination has revealed that severe endometrial changes of the uterine structure occur in majority of the cases, implying that a permanent management is the most preferable solution for the condition. However, the clinical status of the animal as evident from the study helps in deciding whether to perform a surgery or to initiate the medical management, thus increasing the survival chance of the patient.

\section{References}

Bigliardi, E., Parmigiani, E., Cavirani, S., Luppi, A., Bonati, L and Corradi, A. 2004. Ultrasonography and Cyctic Hyperplasi-Pyometra Complex in the Bitch. Reprod. Dom. Anim., 39: 136140
Cox, J.C. And Joshua, J.O., 1979. Gential System. In: Canine Medicine and Therapeutics Edt. Startup, W.G., Sutton, J.B. and Turenor, W.D. Edn1st., Blackwell Scientific, London., Pp 351361

De Bosschere, H., Ducatelle, R., Vermeirsch, H., Van Den Broeck, W. and Coryn, M., 2001. Cystic Endometrial HyperplasiaPyometra Complex in the Bitch: Should the two entities be disconnected? Theriogenology.,55: 1509-1519

Dhaliwal, G.K., England, C.W., and Noakes, D.E., 1998. Oestrogen and Progesterone Receptors in the Uterine wall of Bitches with Cystic Endometrial Hyperplasia / Pyometra. Veterinary Record.,145: 455457

Fakuda, S., 2001. Incidence of Pyometra in Colony-Raised Beagle Dogs. Exp. Anim., 50: 325-328

Feldman, E.C. and Nelson, R.W., 2004. Cystic Endometrial Hyperplasia/ Pyometra Complex. In: Canine and Feline Endocrinology and Reproduction Edt. Kersey, R. Edn.2nd.,W.B.Saunders Company., Pp 852-867

Fransson, B.A., 2003. Systemic Inflammatory Response in Canine Pyometra. Doctoral Dissertation. Acta Universitatis Agriculturae Sueciae Veterinaria

Gandotra, V.K., Singla, V.K., Kochar, H.P.S., Chauhan, F.S. and Dwivedi, P.N., 1994. Haematological and Bacteriological Studies in Canine Pyometra. Indian.Vety. J., 71(8): 816-818

Gobello, C., Castex, G., Klima, L., Rodri'Guez, R. and Corrada, Y., 2003. A Study of two Protocols Combining Aglepristone and Cloprostenol to Treat Open Cervix Pyometra in the Bitch. Theriogenology., 60: 901-908.

Greene, C.E., 2006. In: Infectious Diseases of the Dog and Cat. Edn. 3rd., W. B. Saunders Elsevier,. Pp 1387 
Hagman, R., 2004. New Aspects of Canine Pyometra. Ph.D Dissertation. Swedish University Of Agricultural Sciences, Uppsala

Hagman, R., Kindahl, H., Fransson, B.A., Bergstro“M, A., Stro“M Holst, B. And Lagerstedt, A. S., 2006. Differentiation between Pyometra and Cystic Endometrial Hyperplasia/ Mucometra in Bitches by $\mathrm{PGF}_{2} \alpha$ Metabolite Analysis. Theriogenology, 66: 198-206

Hagman, R., Reezigt, B.J., Ledin, H.B. and Karlstam, E., 2009. Blood Lactate Levels in 31 Female Dogs with Pyometra. Acta. Vet. Scand., 51: 2

Hardie, E.M., and Kruse-Elliott, K., 1990. Endotoxic Shock. Part 1. A Review of Cases. J Vet Intern Med.,4: 258-266

Igna, C., Igna, V., Schuszler, L., Dascălu, R., Sala, A.and Sabău, M., 2009. Oestrus Control with Progestins and Cystic Endometrial Hyperplasia pyometra Complex in the Bitch. Lucrări Stiinłifice Medicină Veterinară., 42(2): 210-214

Kaymaz, M., Baştan, A., Erünal, N., Ve Ark. and Köpeklerde., 1999. Ceh-Pyometra Kompleksinin Tanısinda Labarotuva Bulguların in Kullanılması. Tr J Vet Anim Sci.,23(2): 127-133

Melih, U., Tek, C., Gunduzi, M.C., Sabuncu A., Şenunver, A., Bağcigil, F.A and Bakirel, T., 2012. Optimum Timing for Operation in Bitches with Pyometra related to Endotoxemia. Turk $J$ Vet Anim Sci., 36(1): 35-42

Nyland, T.G. and Mattoon, J.S., 2002. Ovaries and Uterus. In: Small Animal
Diagnostic Ultrasound Edt. Kersey, R. Edn.2nd.,W.B.Saunders; Pp 231-249

Okano, S., Tagawa, M., Hara, Y., Ejima, H., Motoyoshi, S., Urakawa, N., Furakawa, K., Onda, M. and Ogawa, R., 1993. Changes In Reticulo endothelial Function in Dogs with EndotoxinInduced Shock. J. Vet. Med. Sci., 55: 607-611

Renukaradhya, G.J., 2011. Studies on Treatment of Pyometra in Bitches with Antiprogestins. Ph.D. Thesis, Karnataka Veterinary and Animal Sciences University, Bidar, India

Sevelius, E., Tidholm, A.And Thorén-Tolling, K., 1990. Pyometra in the Dog. J Am Vet Med Assoc., 26: 33-38

Sokolowski, J.H., 1992. Metritis Pyometritis. In : Small Animal Reproduction and Causes of Infertility - A Clinical Approach of Diagnosis and Treatment Edt. Thomus, J.B. Edn. 1st., Lea And Febiger., Pp 279-283

Stone, E.A., Littman, M.P., Robertson, J.L. and Bovée, K.C., 1988. Renal Dysfunction in Dogs with Pyometra. $J$ Am Vet Med Assoc., 193: 457-464

Verstegen, J., Dhaliwal, G. and VerstegenOnclin, K., 2008. Mucometra, Cystic Endometrial Hyperplasia, and Pyometra in The Bitch: Advances in Treatment Reproductive Success. Theriogenology.,70(3): 364-374

Wheaton, L.G., Johnson, A.L., Parker, A.J. and Kneller, S.K., 1987. Results and Complications of Surgical Treatment of Pyometra: A Review of 80 Cases. $J$ Am Anim Hosp Assoc., 25: 563-568

\section{How to cite this article:}

Gopal Samantha, T. Sarath, G. Monica, N. Arunmozhi, P. Sridevi and Cecilia Joseph. 2018. Ultrasonographic and Haemato-biochemical Evaluation of Bitches Affected with Cystic Endometrial Hyperplasia-Pyometra Complex. Int.J.Curr.Microbiol.App.Sci. 7(06): 2327-2338. doi: https://doi.org/10.20546/ijcmas.2018.706.278 